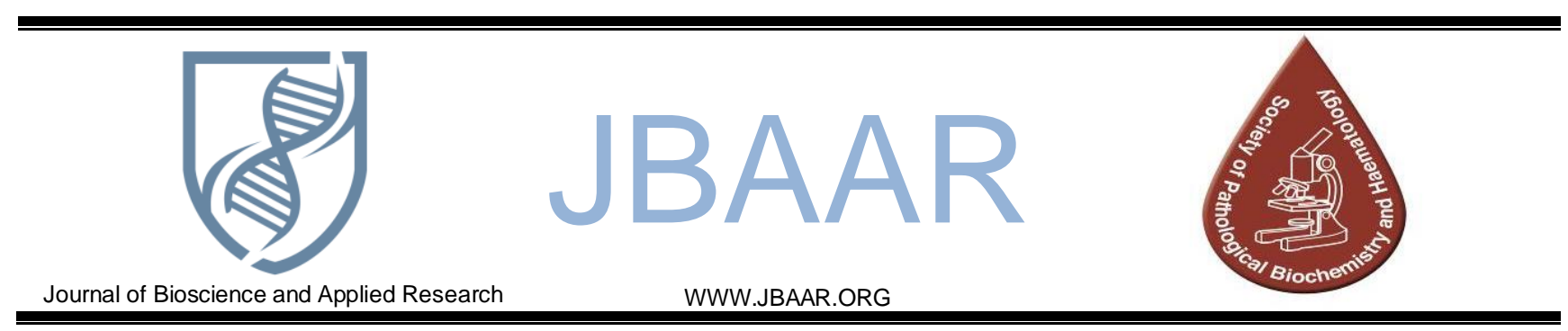

\title{
Flies (Diptera: Calliphoridae, Sarcophagidae, Muscidae) associated with human corpses in Alexandria, Egypt
}

\author{
Tarek I. Tantawi ${ }^{1}$, Ibrahim E. El-Shenawy ${ }^{2}$, Hoda F. Abd El-Salam ${ }^{2}$, Somia A. Madkour ${ }^{2}$, \\ Nevine M. Mahany ${ }^{3}$ \\ ${ }^{1}$ Department of Zoology, Faculty of Science, Alexandria University, Alexandria, Egypt. \\ ${ }^{2}$ Department of Forensic Medicine and Toxicology, Faculty of Medicine, Alexandria University, Alexandria, Egypt. \\ ${ }^{3}$ Forensic Medicine Directorate, Alexandria, Ministry of Justice, Egypt.
}

Received: February 23, 2018. Accepted: May 25, 2018. Published: June 2, 2018

DOI: $10.21608 /$ jbaar.2018.130065

\begin{abstract}
During the period from 20 May 2000 to 8 May 2002, 15 human corpses found in different seasons and habitats in Alexandria, Egypt were investigated for insect evidence. The present study aimed to identify and record the different species of flies infesting the corpses to establish a database for the potential use of insects as forensic indicators in Alexandria. Insect collecting was performed during an autopsy at El-Esaaf Morgue, Kom El-Deka, Alexandria. All the corpses examined were enrolled in death investigations. Larvae of six fly species belonging to three families were collected from the corpses; Calliphora vicina, Chrysomya albiceps, Chrysomya megacephala, and Lucilia sericata (Calliphoridae); Sarcophaga argyrostoma (Sarcophagidae); and Muscina stabulans (Muscidae). These fly species were the initial colonizers of the corpses and, hence, are important in minimum postmortem interval estimates in Alexandria. Larvae of Calliphoridae were the most common and abundant insects, collected from $86.66 \%$ of the corpses and infested corpses in all seasons and habitats. Chr. albiceps was the most common species, invading $73.33 \%$ of the corpses of which $33.33 \%$ of infestations were found in urban, indoor situations. Outdoor infestations of corpses by this species accounted for $40 \%$. Larvae of Chr. albiceps were collected from corpses in all seasons and were found to monopolize six corpses. Chr. megacephala, L. sericata, and S. argyrostoma were able to invade each $20 \%$ of the corpses where they acted as primary flies. S. argyrostoma was found to be a
\end{abstract}


highly indicative species to corpses found in urban, indoor habitats during the warmer seasons. Three cases of forensic entomology interest are presented and discussed.

Keywords: forensic entomology, human corpses, Calliphoridae, Chrysomya albiceps, Egypt.

\section{Introduction}

Medicolegal entomology is the branch of forensic entomology that deals with the study of insects found on corpses to contribute to the time, cause, manner, and place of the investigated death (Byrd and Castner 2010). The time elapsed since death, or postmortem interval (PMI), is a matter of crucial importance in investigations of homicides and other untimely deaths. Such information can help to identify both the criminal and the victim by eliminating suspects and connecting the deceased with individuals reported missing for the same amount of time (Wells and LaMotte 2010). Insect associations with carrion have been divided into two main phases; the precolonization interval and the post-colonization interval (Tomberlin et al. 2011). The precolonization interval begins at the moment of death and includes "exposure" where insects have not yet detected the cadaver, "detection," where insects first locate the cadaver, and "acceptance," when insects assess the quality of the resource for potential oviposition sites. The post-colonization interval begins at the moment of colonization and includes the "consumption phase" and "dispersal phase" during which the insects colonize and feed on the cadaver until all nutrients are removed (Tomberlin et al.2011).

There are two methods for estimating the PMI based on entomological evidence. The first method is development-based in which the estimated age of an immature insect that has fed on a body provides a minimum PMI (Wells and LaMotte 2010; Anderson 2016). The second method uses the process of the succession of arthropod species found on a body (Schoenly and Reid 1987; Kreitlow 2010; Anderson 2016) and can be used to estimate both the minimum and maximum PMI (Schoenly et al. 1992; Wells and LaMotte 2010). In both methods, correct species identification of necrophagous insects is pivotal to their use as evidence in death investigations (Rivers and Dahlem 2014). The rate of development of an insect in a corpse at a particular temperature is species-specific (Greenberg and Kunich 2002; Wells and LaMotte 2010). Also, reliable identification of an insect species is a cornerstone of forensic entomology, primarily because it facilitates access to relevant information stored in published literature and allows scientists to communicate and contextualize their findings effectively (Badenhorst and Villet 2018).

Necrophagous flies in the family Calliphoridae (blowflies) (and to a lesser extent in the families Sarcophagidae (flesh flies) and Muscidae (hosue flies and allies)) are the most frequent insects used in PMI estimations due to their tight association with carrion, ubiquity, and early arrival on carrion (Greenberg and Kunich 2002; Wells and LaMotte 2010; Merritt and De 
Jong 2016). The age of the oldest actively feeding larva of a blowfly collected on a corpse during the first generation is the most precise indicator of the minimum PMI, once its species and thermal history are determined (Greenberg and Kunich 2002).

Tantawi et al. (1996) have conducted field studies on seasonal arthropod succession on exposed rabbit carrion in Alexandria, Egypt. These studies have provided the basis for understanding the species composition and ecology of our local carrion arthropod community, which is fundamental to the application of medicolegal entomology. The present study aims to identify and record the fly species that frequent human corpses in Alexandria to develop a database for application to the field of medicolegal entomology practice in Alexandria.

\section{Materials and Methods}

During the present study, human corpses found by death investigators at different sites in Alexandria were examined for entomological evidence after their arrival to El-Esaaf Morgue, Kom El-Deka, Alexandria, Egypt. Insect specimens were collected within the first 48 hours since the corpses were discovered. At autopsy, samples of all species and stages of insects present were collected directly from all regions of the body. Samples collected from different regions were maintained separately and labeled. All insect samples were transferred to the Forensic Entomology Laboratory of the Department of Zoology, Faculty of Science,
Alexandria University, Alexandria, Egypt for reliable species identification.

At the laboratory, each sample of fly larvae collected from a particular region of the body was divided into two subsamples. Larvae of the first subsample were immediately killed in boiling water and preserved in acetic alcohol (3 parts $70 \%$ ethanol: 1 part glacial acetic acid) (Erzinclioglu 1990). Whole larvae were examined in fluid with a dissection stereomicroscope. Selected specimens of each species were dissected, cleared in a solution of $10 \% \mathrm{KOH}$ at room temperature, and mounted in Berlese fluid (Smith 1986) for examination with a compound microscope. The instar of each preserved larva was determined according to the number of spiracular slits. The first instar with none or one slit, the second instar with two slits, and the third instar with three slits in each posterior spiracle (Smith 1986) Third instars were separated to the species level after Tantawi and El-Kady (1997), Wells et al. (1999), Szpila (2010), Fremdt et al. (2012), Szpila et al. (2015), and Grzywacz et al. (2015, 2017).

Larvae of the second subsample were kept alive and reared at room temperature to the adult stage for species confirmation. Adult flies are identified much easier than larvae especially the younger ones (first and second instars) (Smith 1986; Byrd and Tomberlin 2010). About 50 larvae of the same species were reared in a $200 \mathrm{ml}$ glass container. The bottom of the container contained excess lean ground beef $(\approx 150 \mathrm{gm})$ on $1 \mathrm{~cm}$ of sawdust moistened with a few drops of water to prevent desiccation. Dry sawdust $(5 \mathrm{~cm})$ was then added for the post-feeding larvae to pupariate. 
The mouth of the container was then sealed with a fine mesh cloth fastened with a rubber band to keep other flies from entering and ovipositing in the pabulum. Emerged adult flies were killed in ethyl acetate vapor after attaining full coloration and wing inflation to ensure that all the required taxonomic characters are visible. The flies were then pinned and examined under a stereomicroscope for identification. Accurate identifications of adult calliphorid species were facilitated by the work of Akbarzadeh et al. (2015), Lutz et al. (2018), and Sawaby et al. (2018). Adult sarcophagids were identified through the male genitalia after Salem (1935), Pape (1987), and Sawaby et al. (2018). Adult muscids were identified using the keys of Assis Fonseca (1968), Smith (1986), and Couri (2007).

Voucher specimens are deposited as reference materials in the forensic entomological collection of the Department of Forensic Medicine and Toxicology, Faculty of Medicine, Alexandria University.

Information and data concerning each corpse examined were recorded in a case study form. Insects collected from the corpses examined were categorized by species, instar or stage of development, the habitat where the remains were found, and season of discovery. In this study, the postmortem changes or the stages of decomposition of the human bodies were determined after Amendt et al. (2004). For corpses found burned, the Crow-Glassman Scale (Glassman and Crow1996) was used to describe the extent of body destruction from burning. This scale is divided into five levels, depicting increasing destruction to the body relative to burn injury.

\section{Results}

During the period from 20 May 2000 to 8 May 2002, insect specimens were collected from 15 human corpses at El-Esaaf Morgue, Kom ElDeka, Alexandria, Egypt for identification and potential use as forensic indicators. The corpses belonged to 11 males (one of which was a fetus of seven months old) and four females. The corpses were found exposed (not buried) in different seasons and regions in Alexandria and enrolled in criminal investigations. Four corpses were found in spring, five in summer, four in fall, and only two corpses were found in winter (Table 1). Eleven corpses were located in urban habitats, of which six were found indoors and five were found outdoors, whereas the remaining four corpses were located outdoors in rural habitats (Table 2). The corpses were in the bloated or destruction (aerobic decay) stage of decomposition at the time of collecting entomological evidence.

In this study, larvae of six fly species belonging to three families were found infesting the 15 corpses investigated. The flies were Calliphora vicina Robineau-Desvoidy, Chrysomya albiceps (Wiedemann), Chrysomya megacephala (Fabricius), and Lucilia sericata (Meigen) (Calliphoridae); Sarcophaga argyrostoma (Robineau-Desvoidy) (Sarcophagidae); and Muscina stabulans (Fallén) (Muscidae) (Table 3). Eight corpses were infested with only one species, six corpses with two species, and one corpse with three species. 
Larvae of Calliphoridae were the most common insects infesting $86.66 \%$ (13 cases) of all corpses examined. Sarcophagid and muscid larvae were found only in three and two cases, respectively. The collected larvae represented the first generation of the species of flies that invaded the corpses because no empty puparia were found on or around the corpses. Besides, the head region of the corpses was the main infestation site. This indicates that these fly species were the initial insect colonizers of the corpses examined. It should be noted that, in the present study, the youngest larvae observed in and collected from the corpses were second instars.

The European blue bottle fly $C$. vicina was able to breed in one corpse only during the present study (Table 3, Fig. 1). Larvae of this species were singly found infesting the body of a fetus placed in a refuse container during the beginning of the spring season (2 April 2001) (Table 4) in an urban, outdoor area (Fig. 2). At autopsy, the larvae of C. vicina were in the second and third instars (Table 5).

Chrysomya albiceps, the African hairy maggot blowfly, outnumbered all other fly species frequented human corpses throughout the entire period of study. Larvae of this blowfly were collected from 11 cases which accounted for $73.33 \%$ of all cases studied (Table 3, Fig. 1). This species was attracted to three corpses in spring as well as in summer, four corpses in fall, and one corpse only during the later part of winter (Table 4). Eight corpses infested with Chr. albiceps larvae were located in urban situations, of which five were indoor corpses representing approximately $50 \%$ of all cases infested with this species (Fig. 2). Also, urban, indoor infestations of corpses with Chr. albiceps predominated all other species infestations of the 15 corpses studied by $33.33 \%$ (Fig. 2). However, outdoor infestations with this species in urban and rural areas comprised $40 \%$ of all other species infestations of the corpses examined during the period of study (Fig. 2).

During this study, the most dominant instar of Chr. albiceps observed in corpses was the feeding third instar occupying 10 cases, followed by the post-feeding third instar occupying nine cases; of the 11 cases infested with this species (Table 5). Intact puparia of $C h r$. albiceps species were collected on and around three corpses only (Table 5). No other fly puparia were observed in any case during the present study.

In this study, Chr. albiceps larvae monopolized six corpses, whereas they were found associated with smooth maggots of other fly species in five corpses. In mixed-species infestations, larvae of Chr. albiceps were associated with other larvae of Chr. megacephala in three cases, L. sericata in two cases, and $S$. argyrostoma in one case only (Table 6). In all cases in which mixed-species infestations occurred, Chr. albiceps was a secondary fly ovipositing in corpses after oviposition or larviposition of other fly species took place. This was evident as the second instars of this species were still present in large numbers in carrion at the time of collecting while most larvae of all other species were in the feeding third or postfeeding third instars. 
The Oriental latrine flies Chr. megacephala has invaded three corpses, accounting for $20 \%$ of all cases studied (Table 3, Fig. 1), of which one corpse was found in spring and two corpses were found in summer (Table 4). This species invaded one corpse located indoors in an urban area and two outdoor corpses in rural regions (Fig. 2). Rural, an outdoor infestation of this species was $13.33 \%$ of all cases studied (Fig. 2). Larvae observed and collected were in the feeding third and post-feeding third instars (Table 5). In the three cases, Chr. megacephala was a primary species ovipositing in carrion before $C h r$. albiceps.

The common green bottle fly or sheep blowfly L. sericata has bred in three corpses during this study comprising $20 \%$ of all cases (Table 3, Fig. 1). Two corpses were found in spring and one corpse was found in winter (Table 4). This species was attracted to two corpses in urban habitats, of which one corpse was found indoors and the other one was found outdoors, and to one corpse only in a rural, outdoor habitat (Fig. 2). The infestation of corpses with $L$. sericata larvae in urban habitats presented $13.32 \%$ of all cases examined (Fig. 2). Larvae observed and collected were second, third, and post-feeding third instars in all the three cases (Table 5). In these three cases, L. sericata was a primary fly, followed by the secondary flies of Chr. albiceps in two cases and $M u$. stabulans in one case.

The flesh flies $S$. argyrostoma larviposited in three corpses presenting $20 \%$ of all cases studied which was the same as Chr. megacephala and L. sericata (Table 3, Fig. 1). One corpse was present in spring and the other two were found in summer (Table 4). All three cases infested with this species were found in urban, indoor situations (Fig. 2). Therefore, $S$. argyrostoma ranked second in the urban indoor infestation of corpses after Chr. albiceps (Fig. 2). Feeding third and post-feeding third instars of $S$. argyrostoma were collected from two cases, whereas second instars of this species were collected from one corpse only (Table 5). In this study, S. argyrostoma was able to monopolize one corpse, associated with Chr. megacephala and Chr. albiceps in another corpse, and associated with the muscid $M u$. stabulans in a third corpse. In mixed-species infestations, S. argyrostoma was a primary fly like Chr. megacephala and $L$. sericata.

The muscid fly $M u$. stabulans was able to oviposit in two corpses only throughout the study (Table 3, Fig. 1). One corpse was found in summer, while the other was found in winter (Table 4). The summer corpse was located indoors in an urban area, whereas the winter corpse was located outdoors in a rural region (Fig. 2). The summer corpse was infested with only third instars, while the winter corpse was infested with second and third instars (Table 5). Muscina stabulans infested the two corpses as a secondary fly which frequented the summer corpse after $S$. argyrostoma and the winter corpse after $L$. sericata.

During the present study, three cases were of special interest to forensic entomology. In the first case, the body of a 40-year-old man was found burned in spring (15 April 2001) in an urban, outdoor region at El-Amyria District, west of Alexandria. An autopsy revealed that the burnt 
corpse corresponded to level \# 3 of the CrowGlassman Scale. At this level of burning, the body was charred with cracked skin, the head was present although identity is nonrecognizable, and the major portions of the arms and/or legs were missing. Despite this extent of burn injury, the remains were still attractive to blowflies. Numerous larvae of L. sericata and Chr. albiceps were actively feeding in the head region.

The second case belonged to a decomposed body of a 30- year-old man who was found heavily wrapped in an old blanket during summer (28 August 2000) in an urban, indoor habitat west of Alexandria (Karmouze District). Blanketing was not sealed at the head or feet. At autopsy, the head and abdominal regions were occupied by numerous post-feeding third instars of $S$. argyrostoma and a few feeding third instars of Mu. stabulans.

In the third case, the body of a 67-yearold man was found during winter (29 January 2001) in a rural, outdoor region, west of Alexandria (El-Nahda District). The corpse was partially covered with soil with the arms and legs exposed. When examining the corpse at El-Esaaf Morgue, the facial region was extensively infested with the larvae of $L$. sericata and Mu. stabulans.

\section{Discussion}

To the best of our knowledge, the present work is the first in Alexandria to record the fly species associated with human remains to establish reliable baseline information of the use of insects as postmortem interval indicators. Four calliphorids, C. vicina, Chr. albiceps, Chr. megacephala, and L. sericata; one sarcophagid, $S$. argyrostoma; and one muscid, $M u$. stabulans were the initial colonizers of the 15 corpses examined. Hence, these fly species are of forensic importance in Alexandria and can be used to estimate the postmortem interval. The larvae collected were the first generation of these six fly species in carrion because no empty puparia were found on or around the corpses. The head region of the corpses was the site mainly infested with maggots. Mouth, nose, and ears are the preferred oviposition/ larviposition sites of carrion flies (Greenberg and Kunich 2002; Pacheco et al. 2017).

In this study, calliphorid larvae infested $86.66 \%$ of the corpses and were present in corpses in all seasons as well as in urban and rural habitats. Tantawi et al. (1996) have noted that calliphorid larvae were the most dominant and abundant insects infesting all the rabbit carcasses exposed in all seasons in Alexandria. Calliphorids (blowflies) are typically the first insects to find a body, often before the police do. Because most bodies are discovered in the first few weeks, blowflies are encountered more frequently in death investigations and can reveal a time of death more accurately than their successors (Greenberg and Kunich 2002; Byrd and Castner 2010).

All the fly species recorded in this study, except Chr. megacephala, have also bred in exposed rabbit carcasses in Alexandria during a seasonal study on carrion arthropod succession conducted in 1988 and 1989 (Tantawi et al. 1996).) Chr. megacephala was first recorded in Egypt in 1988 when one adult was caught by a beef-baited fly trap in Moharrem Bey District, Alexandria (Tantawi et al. 1996). This species has dispersed from its original distribution in the 
Oriental and Australasian Regions throughout Africa, the Middle East, and the Americas (Wells and Kurahashi 1994; Martinez-Sanchez et al. 2001; Akbarzadeh et al. 2015; Badenhorst and Villet 2018). In Europe, it has also been recorded in Alicante, southeastern Spain (MartinezSanchez et al. 2001), and Lisbon, Portugal (Castro and Garcia 2009). In Egypt, Chr. megacephala has been found to infest rabbit carcasses in Burg El-Arab, Alexandria (El-Gaffar et al. 2008) and Abbassyia, Cairo (Abd El-Bar et al. 2016). This species prefers a wide range of temperature which explains why this species has spread around the world so successfully (Richards et al. 2009).

During the present study, Chr. megacephala has bred in three corpses in spring and summer of which one was found in an urban, indoor habitat and two were discovered in rural, outdoor habitats. It was a primary fly in the three corpses, followed by Chr. albiceps. In a seasonal study on insect succession on carrion in Alexandria, El-Samad and Youssef (2016) recorded Chr. megacephala in control and amitriptyline- injected rabbit carcasses in spring and summer only. Chr. megacephala is common around human dwellings where it feeds on dead fish, carcasses, human excrement, fruits, and sweets (Wells 1991). It is well documented as an early and dominant colonizer of human corpses in forensic cases (Cheong et al. 1973; Lee et al. 2004; Sukontason et al. 2007; Badenhorst and Villet 2018). Goff (1991) has recovered Chr. megacephala larvae from three indoor and 14 outdoor cases of human corpses in Hawaii. Abdullah et al. (2017) found that Chr. megacephala was the most dominant species that invaded indoor human corpses in Malaysia.

During the present study, Chr. albiceps larvae were the most dominant and common larvae infesting $73.33 \%$ of the corpses, of which $33.33 \%$ of infestations were confined to urban, indoor corpses and $40 \%$ of infestations were recorded in outdoor (urban and rural) corpses. Also, larvae of this species invaded corpses in all seasons. Therefore, Chr. albiceps is the most important fly species in postmortem interval estimates during death investigations in Alexandria. In Egypt, these species have been reported to be the dominant carrion colonizer in Alexandria (El-Kady et al. 1994; Tantawi et al. 1996; El-Ghaffar et al. 2008), El-Qalyubiya (Abd El-Bar and Sawaby 2011), Assiut (Galal et al. 2009), Cairo (Abd El-Bar et al. 2016), and Qena (Aly et al. 2017). El-Mehy et al. (2015) found that Chr. albiceps was the most common species infesting nine of the fifteen human corpses examined in the Middle Delta of Egypt. They recorded this species in six urban cases and three rural cases during spring (five cases), summer (two cases), and winter (two cases). Zerriya et al. (2015) have found that Chr. albiceps was the most dominant species invading dog and rabbit carcasses placed indoors and outdoors in Nasr city, Cairo during summer. In Brazil, Carvalho and Linhares (2001) stated that Chr. albiceps is a potential species for postmortem interval estimates due to its high dispersal ability and early arrival at carrion but it is of no value as an indicator of a particular habitat type, since it does not appear to display habitat specificity. Chr. albiceps has been frequently encountered in death investigations (Grassberger et al. 2003; Vanin et al. 
2009, 2011; Al-Mesbah et al. 2011; Kosmann et al. 2011; Lambiase and Camerini 2012; Alajimi et al. 2016; Ramos-Pastrana and Wolff 2017).

Chrysomya albiceps is well known as a warmer species (Grassberger et al. 2003; AlShareef and Al-Quarshi 2016) which is very common and abundant in South Palaearctic (including the Mediterranean to Central Europe), Afrotropical, Oriental (from India to China) and Neotropical Regions (Grassberger et al. 2003). In Europe, this species extends its distribution from southern to northern regions during hot summers (Grassberger et al. 2003; Grassberger and Frank 2004) In South Africa, Chr. albiceps females do not lay eggs in winter (Smit 1931). In southeastern Spain, the presence of this species is extremely rare in winter (Arnaldos et al. 2001). Tantawi et al. (1996) have noted the complete absence of $C h r$. albiceps larvae in rabbit carcasses exposed in winter in Moharrem Bey District, Alexandria. However, in our study, the larvae of this species were found infesting one corpse at the end of the winter season when the temperature was above its normal level during this period. Ibrahim et al. (2013) have collected larvae of Chr. albiceps from guinea pig carcasses during winter in Benha, Egypt.

In this study, Chr. albiceps monopolized six corpses and acted as a secondary species in five corpses. In the five mixed-species infestations, the larvae of this species were associated with other larvae of Chr. megacephala, L. sericata, and $S$. argyrostoma. Chr. albiceps is typically a secondary invader of carrion (Tantawi et al. 1996). The second and third instars of this species are facultative predators on other fly larvae present in carrion (Zumpt 1965). In Vienna, Austria, Grassberger and Frank (2004) found that the second and third instars of Chr. albiceps almost monopolized the pig carcass exposed in summer as a result of their intense predation on other fly larvae associated with them in carrion. They also stated that this aggressive feeding behavior of second and third instars of Chr. albiceps on other carrion-breeding larvae could reset the postmortem insect clock by clearing a corpse of all earlier arrivers.

During the present study, intact puparia of Chr. albiceps were collected from three cases. No other fly puparia were collected in any case in this study. Post feeding larvae of Chr. albiceps have a high tendency to pupariate in great numbers around and beneath carrion, compared with those of other calliphorids and sarcophagids which usually migrate away from the carrion before pupariation (Tantawi et al. 1996). This suggests that in future studies, specimen collecting should be achieved at the death scene and not at the morgue.

During the present study, L. sericata was a primary invader of two corpses in spring and only one corpse in winter, representing $20 \%$ of all cases examined. Two corpses were found in urban habitats, of which one corpse was found indoors and the other one was found outdoors. The third corpse was located in a rural, outdoor habitat. This species ranked third after Chr. albiceps and S. argyrostoma in infesting urban corpses. An infestation of urban corpses by this species accounted for $13.32 \%$ of all cases. In Moharrem Bey District, Alexandria L. sericata was a primary species that bred successfully in exposed rabbit 
carcasses in all seasons, except summer (Tantawi et al. 1996). In the southeastern Iberian Peninsula, this species predominated chicken carcasses during spring, was less abundant in fall and winter, and did not breed in summer (Arnaldos et al. 2001).

Lucilia sericata is a synanthropic fly very common around human habitations in the Holarctic Region but occurs throughout the world (Grassberger and Reiter 2001; Byrd and Castner 2010; Williams et al. 2014). It is one of the most prevalent species collected at crime scenes and used for the estimation of the minimum postmortem interval (Grassberger and Reiter 2001; Anderson and Cervenka 2002; Greenberg and Kunich 2002). Lucilia sericata is one of the earliest arriving fly species on remains, with oviposition occurring typically only a few hours after death (Castner and Byrd 2010). Adults of L. sericata are well known to frequently open and sunny habitats (Nuorteva 1977; Matuszewsk et al. 2013). However, Peschke et al. (1987), in Germany, found that this species was more abundant in a forest than in cleaning habitats. Mariluis and Schnack (1989), in Argentina, have noted that L. sericata did not show any preference for shaded or sunny places. Smeeton et al. (1984), in Auckland, New Zealand, reported that $L$. sericata laid eggs on 18 of 20 human corpses discovered indoors. In British Columbia, an analysis of 42 human death investigations revealed that this species was collected indoors in 86\% of cases (Anderson 1995). Greenberg and Kunich (2002) have identified $L$. sericata larvae collected from a body found indoors in an urban area of Toronto, Canada.
During this study, C. vicina invaded only one corpse belonging to a fetus found in a garbage bin in early spring in an urban, outdoor habitat. The second and third instars of this species were the only larvae infesting the corpse. Calliphora vicina was able to breed in carrion during winter only at Moharrem Bey District where it acted as a primary fly (Tantawi et al.1996). During a seasonal arthropod succession study on carrion conducted in the southeastern Iberian Peninsula, Arnaldos et al. (2001) found that $C$. vicina was a primary and the dominant species in carrion during winter. They also found that this species acted as a primary fly during spring and fall but its larval abundance in carrion was much lower than in winter; whereas, in summer, it did not breed in carrion.

Calliphora vicina is a cosmopolitan (Rognes 2002) and eusynanthropic fly which is closely tied to the human environment and frequently showing endophilic tendencies (Greenberg and Povolny 1971). It is a cold-loving species that occur in winter in the subtropics, in spring and fall in the temperate zone, and in summer in the subpolar zone (Greenberg and Povolny 1971). Adults are attracted to fruit, decaying meat, and feces; the larvae develop chiefly in carrion (Greenberg and Povolny1971). Calliphora vicina is often found on human corpses in forensic cases, especially in urban situations, and can find and oviposit on concealed bodies (Greenberg and Kunich 2002).

Mohamed (1984) noted that in Alexandria, the population of C. vicina begins building in fall, increases during winter, and then decreases in May. However, since the last two decades, the duration of the existence of $C$. vicina in Alexandria has been 
dramatically shortened. Adults and larvae of this species are hardly seen on carrion. This would be attributed to the prevalence of warmer climates over prolonged periods in the cooler seasons as a result of climate change (T.I. Tantawi, unpublished data). Greenberg (1991) noticed that higher temperatures around $30.0^{\circ} \mathrm{C}$ accelerate the development of feeding instars of $C$. vicina, but the post-feeding larvae fail to pupariate and subsequently die.

In the present study, S. argyrostoma invaded three corpses in spring and summer, accounting for $20 \%$ of all cases investigated. This species was singly found in one corpse and associated with other fly species in the other two corpses where it acted as a primary species. In Moharrem Bey District, Alexandria, $S$. argyrostoma was able to breed in rabbit carcasses only during fall and was a primary fly with other sarcophagid and calliphorid flies (Tantawi et al. 1996).

Sarcophaga argyrostoma occurs in all zoogeographical regions (Verves et al. 2018) due to its culturophily and synanthropic (Povolny and Verves 1997). The females are larviparous, however, some cases of oviposition have occurred in laboratory-reared colonies (Grassberger and Reiter 2002). The adult flies visit decaying substrates, feces, and carcasses and also feed at flowers (Povolny and Verves 1997). Hafez (1940) stated that this species is the most common species of the genus Sarcophaga s.l. in Egypt, where it prefers larvipositing in larger carcasses of horses, donkeys, and dogs rather than on smaller carcasses as the latter desiccate more rapidly under the higher temperatures.
It is of interest to note that, in this study, the three corpses infested with S. argyrostoma were located in urban, indoor habitats. This species, therefore, seems to be a highly indicative species to corpses found in such situations. Benecke (1998) found that the larvae of $S$. argyrostoma were the only larval species colonizing a corpse lying on the balcony of a flat on the eighth floor in Cologne, Germany, for 25 days. In a town near Toronto, Canada, larvae of this species infested a female body found indoors during a triple murder case (Greenberg and Kunich 2002).

In this study, Mu. stabulans has oviposited as a secondary fly in two corpses only. The first corpse was found in summer in an urban, indoor habitat; while the second corpse was located in winter in a rural, outdoor area. Tantawi et al. (1996) has recorded this muscid species as a secondary invader of carrion in winter only. It should be noted that, in the present study, the summer corpse was wrapped in a blanket. This case will be discussed below.

Muscina stabulans is a cosmopolitan species (Skidmore 1985). Adults of this eusynanthropic fly are frequently found in houses or near human habitation, especially in the open around stables, poultry houses, and on the walls of outside lavatories (Smith 1986). The larvae are found in a wide range of media including rotting fungi, fruits, broken eggs, excrement, and carrion (Smith 1986). They appear to be saprophagous in the first instar and predaceous on other fly larvae in the second and third instars (Skidmore 1985).

During the present study, three cases were found to have important implications for the estimation of postmortem interval by 
entomological techniques. The first case belonged to a male body which was burned at level \# 3 of the Crow-Glassman Scale (Glassman and Crow1996) and infested with larvae of the calliphorids $L$. sericata and Ch.albiceps. A Grow-Glassman Scale level \#3 defines a charred body with major portions of the arms and/or legs missing and the head is nonrecognizable. A study from Hawaii has shown that insects colonize burnt remains in a manner different from unburnt remains (Avila and Goff 1998). In this Hawaiian study, the pig carcasses were burned to give a Crow-Glassman Scale level \# 2 burn. At level \# 2, the body is intact and recognizable but most often exhibits a varying degree of charring. The arthropod fauna which colonized the burnt and unburnt carcasses were the same but appeared earlier on the burnt carcasses presumably due to the openings caused by the cracked skin. The burnt carcasses attracted much more oviposition by Chr. megacephala and Chr. rufifacies (Macquart) than the unburnt carcasses showing that burnt carcasses are still extremely attractive to calliphroid flies. Calliphroid oviposition occurred one to 4 days earlier on the burnt carcasses than the control carcasses. These differences could alter a postmortem interval estimate by entomological evidence in cases involving the burning of a corpse. If a postmortem interval estimate was based on arthropod succession patterns for unburned carcasses, the estimate would be greater than the actual time frame because of the successional waves arriving one to 4 days earlier due to earlier oviposition.

Other studies had previously suggested that fly oviposition was deterred (Catts and Goff 1992) and larval development was retarded by burning (El-Kady et al. 1994), but these no doubt depend on the level of burning and amount of incineration.

In a study conducted to compare the rate decomposition and insect succession between burnt and partially burnt rabbit carcasses placed in different habitats (agricultural, desert, and urban) in Riyadh, Saudi Arabia, Mashaly (2016) found that burning has no effect on the rate of decomposition but has an effect on insect succession. Also, he found significant distinctions in the insect communities between unburnt carcasses and burnt carcasses that can be used as postmortem indicators. In two cases in Italy, insect evidence (primarily larval calliphroid and sarcophagid flies) could still be used to determine the time since death, although both victims were burned (Introna et al. 1998).

In the second case of the present study, larvae of S. argyrostoma and $M u$. stabulans were infesting a male body which was found heavily wrapped in an old blanket during summer in a basement of a building located in an urban area, west of Alexandria. The blanketing was not sealed at the head or feet. No calliphroid larvae were found. This indicates that wrapping has prevented calliphroid females to oviposit on the corpse. However, C. vicina laid eggs on a body wrapped in a quilt and covered with plastic garbage bags, tied with a rope, and placed in a basement of a twostory apartment building in Chicago (Greenberg and Kunich 2002). It has been shown, in death investigations, that although blowflies were able to invade wrapped corpses found indoors (Anderson 2010) and outdoors (Goff 1992), oviposition has been significantly delayed. Sarcophagidae may be the only carrion-fly larvae found on a body that is 
physically isolated (Wells et al. 2001). This may, in part, reflect the fact that, in contrast to other forensically important flies, sarcophagids deposit live larvae rather than eggs, and these may be dropped in the vicinity of the corpse when an adult female cannot physically reach the body. (Denno and Cothran 1976). Muscina stabulans was able to oviposit on a body discovered under a large heap of clothing in a third-floor apartment in the city of Vienna (Grassberger et al. 2003). The type and extent of the wrapping may affect the insect colonization pattern of the remains (Anderson 2010).

Concerning the third case, larvae of $L$. sericata and $M u$. stabulans were found colonizing a corpse lightly covered with soil in winter in a rural, outdoor habitat west of Alexandria. Nuorteva (1977), working in a forensic case in Finland, has found that blowflies were not able to oviposit on a corpse lightly covered by soil. In contrast, $M u$. assimilis (Fallén) oviposited on this corpse. He stated that flies of the genus Muscina RobineauDesvoidy have the peculiar ability to oviposit without immediate contact with the corpse. Females of Muscina are capable of laying their eggs on the soil covering the body (Lundt 1964). The emerging larvae can crawl through the soil to a depth of $10 \mathrm{~cm}$, but they are unable to reach bodies buried at depths of 25 and $50 \mathrm{~cm}$ (Lundt 1964). Gunn and Bird (2011) have shown that L. sericata and $M u$. stabulans can colonize pig liver baits buried in loose soil at a depth of 10 and $40 \mathrm{~cm}$, respectively, where the eggs of both species were laid on the surface of the soil.

Although estimation of the postmortem interval was beyond the aim of this study, several recommendations are suggested. Future studies should be conducted on a larger number of corpses to aid in more understanding of the biology and ecology of carrion flies in Alexandria. For reliable and accurate estimation of the postmortem interval in cases associated with insects, the forensic entomologist should gather and process the relevant entomological and environmental data at the death scene. This procedure would be facilitated by developing protocols for cooperation between the forensic entomologists and various law enforcement agencies, medical examiners, and coroners.

Table 1. Number $(\%)$ of human corpses examined for insect evidence in different seasons in Alexandria, Egypt during 20 May 2000 - 8 May 2002

\begin{tabular}{ccccc}
\hline \hline Spring & Summer & Fall & Winter & Total \\
\hline $4(26.66)$ & $5(33.33)$ & $4(26.66)$ & $2(13.33)$ & 15 \\
\hline
\end{tabular}


Table 2. Number (\%) of human corpses examined for insect evidence in different habitats in Alexandria, Egypt during 20 May 2000 - 8 May 2002

\begin{tabular}{|c|c|c|c|c|}
\hline \multicolumn{2}{|c|}{ Urban } & \multicolumn{2}{|c|}{ Rural } & \multirow[t]{2}{*}{ Total } \\
\hline Indoors & Outdoors & Indoors & Outdoors & \\
\hline $6(40)$ & $5(33.33)$ & - & $4(26.66)$ & 15 \\
\hline
\end{tabular}

Table 3. Classified list of fly species recovered from 15 cases of human corpses found in Alexandria, Egypt during 20 May 2000 - 8 May 2002

\begin{tabular}{llc}
\hline \hline Family & Species & Number of cases \\
\hline Calliphoridae & Calliphora vicina & 1 \\
& Chrysomya albiceps & 11 \\
& Chrysomya megacephala & 3 \\
& Lucilia sericata & 3 \\
Sarcophagidae & Sarcophaga argyrostoma & 2 \\
\hline Muscidae & Muscina stabulans & 3 \\
\hline
\end{tabular}


Table 4. Number of cases of which each fly species was recovered from human corpses in different seasons in Alexandria, Egypt during 20 May 2000 - 8 May 2002

\begin{tabular}{|c|c|c|c|c|}
\hline \multirow[t]{2}{*}{ Fly species } & \multicolumn{4}{|c|}{ Season } \\
\hline & Spring & Summer & Fall & Winter \\
\hline Calliphora vicina & 1 & - & - & - \\
\hline Chrysomya albiceps & 3 & 3 & 4 & 1 \\
\hline Chrysomya megacephala & 1 & 2 & - & - \\
\hline Lucilia sericata & 2 & - & - & 1 \\
\hline Sarcophaga argyrostoma & 1 & 2 & - & - \\
\hline Muscina stabulans & - & 1 & - & 1 \\
\hline
\end{tabular}


Table 5. Number of cases of which each stage of development of fly species occurred on human corpses found in Alexandria, Egypt during 20 May 2000 - 8 May 2002

Fly species
Stage of development

\section{Post-}

2nd instar 3rd instar feeding 3rd instar

\begin{tabular}{lcccc}
\hline Calliphora vicina & 1 & 1 & - & - \\
Chrysomya albiceps & 5 & 10 & 9 & 3 \\
Chrysomya megacephala & - & 3 & 3 & - \\
Lucilia sericata & 3 & 3 & 3 & - \\
Sarcophaga argyrostoma & 1 & 2 & 2 & - \\
Muscina stabulans & 1 & 2 & - & - \\
\hline
\end{tabular}

Table 6. The occurrence of Chrysomya albiceps larvae with other fly larvae on human corpses found in Alexandria, Egypt during 20 May 2000 - 8 May 2002

Fly species associated with Chrysomya albiceps

Number of cases

Chrysomya megacephala 


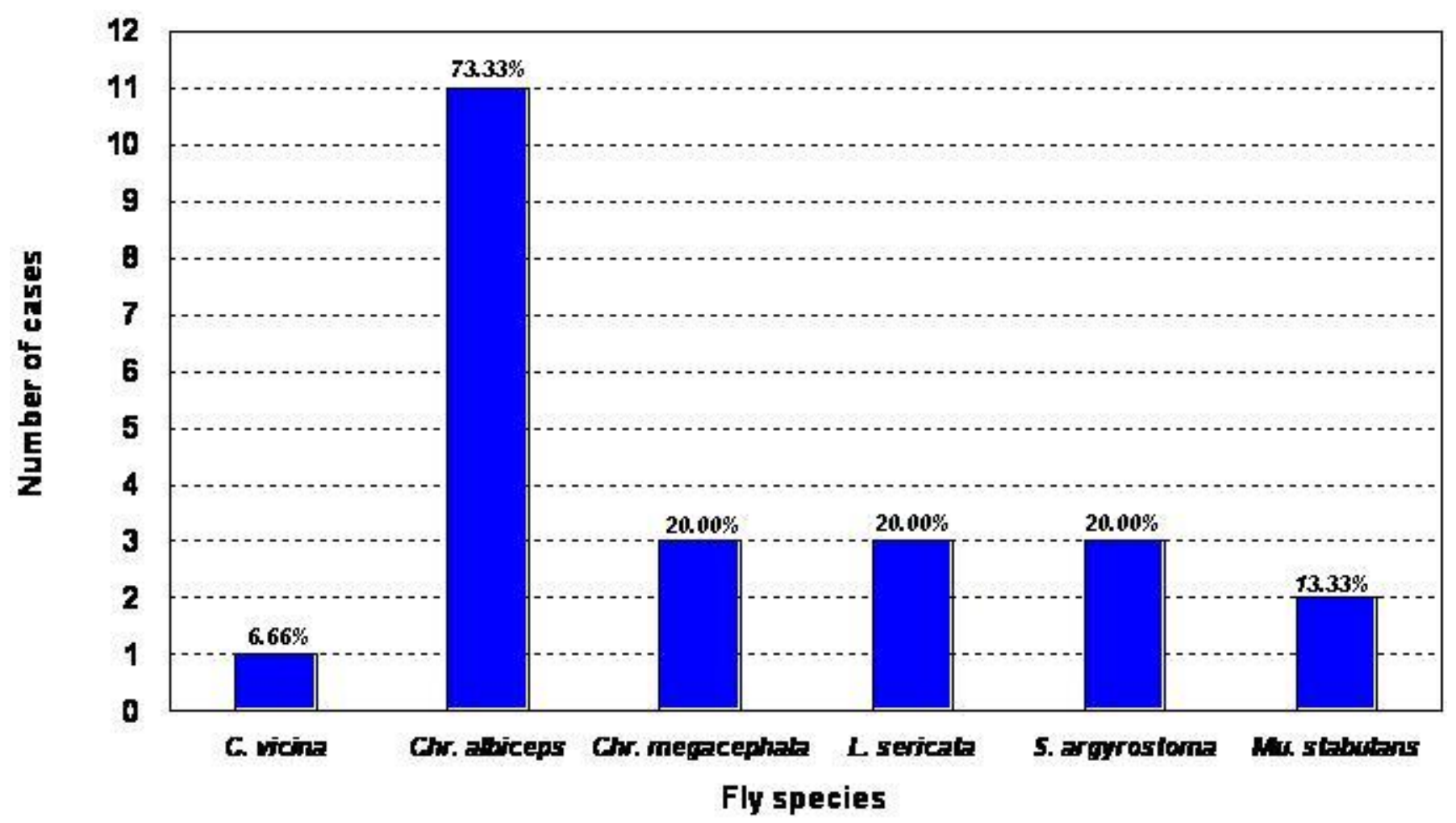

Fig. 1. Fly species recovered from 15 cases of human corpses found in Alexandria, Egypt during 20 May 2000 - B May 2002. 


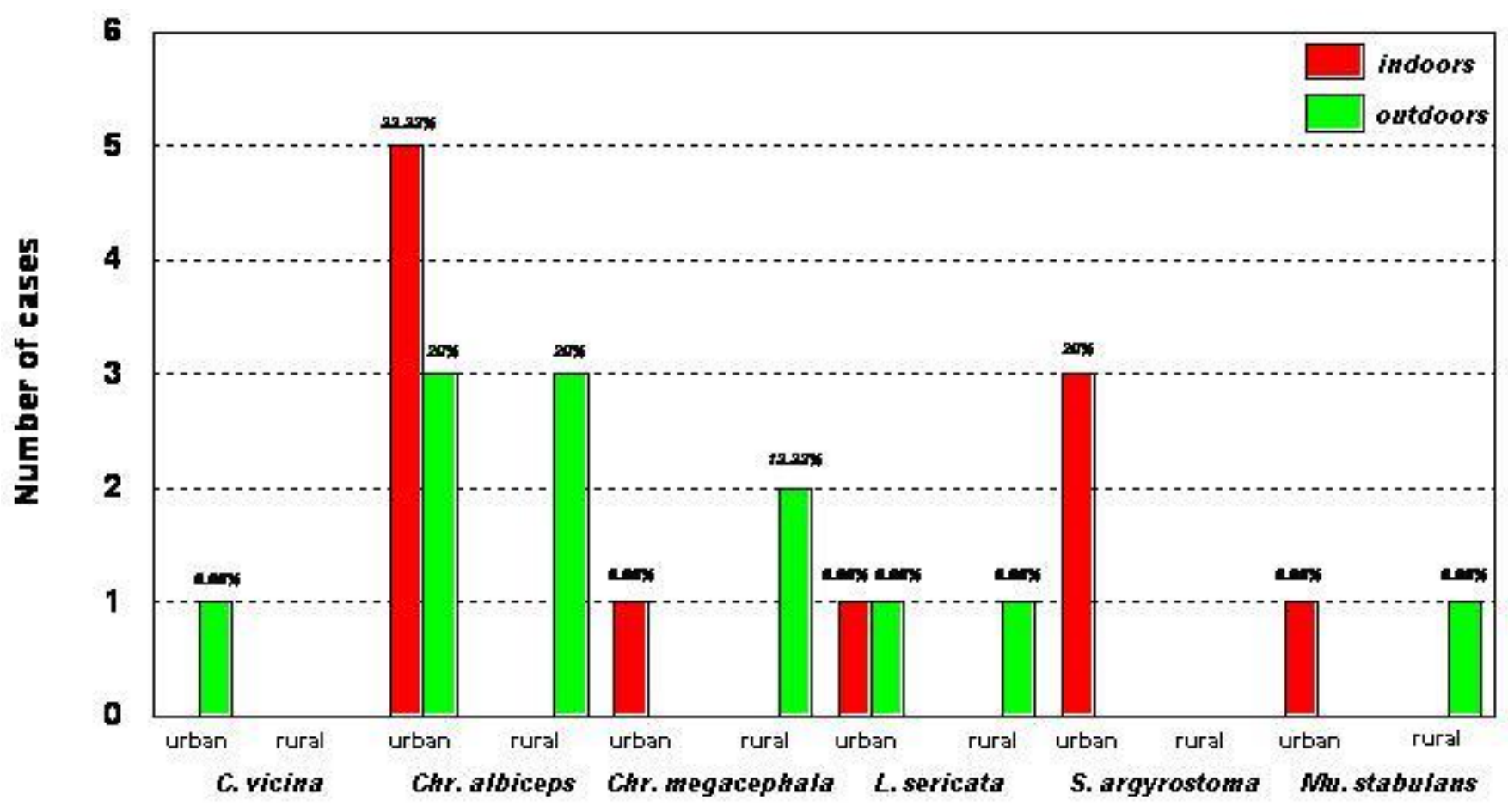

Fly species

\section{Fig. 2. Fly species recovered from 15 human corpses found in Alexandria, Egypt and the habitats in which the remains were found during 20 May 2000 - B May 2002.}

\section{References}

Abd El-bar, M.M. and R.F. Sawaby, R.F.2011.A preliminary investigation of insect colonization and succession on remains of rabbits treated with an organophosphate insecticide in El-Qalyubiya Governorate of Egypt. Forensic Sci. Int. 208: e26-e30.

Abd El-Bar, M.M., Sawaby, R.F., El-Hamouly, H., and Hamdy, R. 2016. A preliminary identification of insect successive wave in Egypt on control and zinc phosphide-intoxicated animals in different seasons. Egypt. J. Forensic Sci. 6: 223-234.

Abdullah, S.R., Omar, B., Salleh, A.F.M., Othman, H., and Wahid, S. A. 2017. Comparative fly species composition on indoor and outdoor forensic cases in Malaysia. J. Forensic Legal Med. 45: 41-46.

Akbarzadeh, K., Wallman, J.F., Sulakova, H., and Szpila, K. 2015. Species identification of Middle Eastern blowflies (Diptera: Calliphoridae) of 
forensic importance. Parasitol. Res. 114:14631472.

Alajimi, R.A., AlGhufaili, H., Farrukh, A., Aljohani, H., and Mashaly, A.M.A. 2016.First report of necrophagous insects on human Corpses in Riyadh, Saudi Arabia. J. Med. Entomol. 53: 1276-1282.

Al-Mesbah, H., Al-Osaimi, Z., and El-Azazy, O.M.E. 2011. Forensic entomology in Kuwait: the first case report. Forensic Sci. Int. 206: 25-26.

Al-Shareef, L.A.H., and Al-Qurashi, S.I.D. 2016. Study of some biological aspects of the blowfly Chrysomya albiceps (Wiedemann 1819) (Diptera: Calliphoridae) in Jeddah, Saudi Arabia. Egypt. J. Forensic Sci. 6: 11-16.

Aly, M.Z.Y., Osman, K.S.M., Galal, F.H., and Ali, G.H.M. 2017. Comparative study on outdoor and indoor forensic insects encountered on rabbit corpses in Upper Egypt. ISOR J. Pharm. Biol. Sci. 12: 41-54.

Amendt, J., Krettek., R., and Zehner, R. 2004. Forensic entomology. Naturwissenschaften 91: $51-65$.

Anderson, G.S. 1995. The use of insects in death investigations: analysis of cases in British Columbia over a five year periods. Can. Soc. Forensic Sci. J. 28: 277-292.

Anderson, G.S. 2010. Factors that influence insect succession on carrion, pp. 201-250. In: J.H. Byrd and J.L. Castner (eds), Forensic entomology: the utility of arthropods in legal investigations, 2nd edition, CRC Press, Boca Raton, Florida.

Anderson, G.S. 2016. Human decomposition and forensics, pp. 541-560. In: M.E. Benbow, J.K.Tomberlin, and A.M.Tarone (eds), Carrion ecology, evolution, and their applications. CRC Press, Boca Raton, Florida.

Anderson, G.S. and Cervenka, V.J. 2002. Insects assoiated with the body: their use and analyses, pp. 174-200. In: W.D. Haglund and M.H. Sorg (eds), Advances in forensic taphonomy- Methods, theory, and archaeological perspectives. CRC Press, Boca Raton, Florida.

Arnaldos, I., Romera, E., Garcia, M.D., and Luna, A. 2001. An initial study on the succession of sarcosaprophagous Diptera (Insecta) on carrion in the southeastern Iberian Peninsula. Int. J. Legal Med.114: 156-162.

Assis Fonseca, E.C.M. 1968. Diptera Cyclorrhapha Calyptrata: Section (b) Muscidae. Handbk. Ident. Br. Insects 10 (4b): 1-119.

Avila, F.W., and Goff, M.L.1998. Arthropod succession patterns onto burnt carrion in two contrasting habitats in the Hawaii Islands. J. Forensic Sci. 43: 581-586.

Benecke, M. 1998. Six forensic entomology cases: description and commentary. J. Forensic Sci.43: 797-805.

Badenhorst, R. and Villet, M.H. 2018. The uses of Chrysomya megacephala (Fabricius, 1794) 
(Diptera: Calliphoridae) in forensic entomology. Forensic Sci. Res. 3: 2-15.

Byrd, J.H., and J.L. Castner, J.L. (Eds). 2010. Forensic entomology: the utility of arthropods in legal investigations, 2nd edition, CRC Press, Boca Raton, Florida.

Byrd, J.H. and Tomberlin, J.K. 2010. Laboratory rearing of forensic insects, pp. 177-200. In: J.H. Byrd and J.L. Castner (eds), Forensic entomology: the utility of arthropods in legal investigations, 2nd edition, CRC Press, Boca Raton, Florida.

Carvalho L.M.L. and Linhares, A.X. 2001. Seasonality of insect succession and pig carcass decomposition in a natural forest area in southeastern Brazil. J. Forensic Sci. 46: 604-608.

Castro, C.P., and Garcia, M.D. 2009. First record of Chrysomya megacephala (Fabricius, 1794) (Diptera, Calliphoridae) from Portugal. Graellsia 65: 75-77.

Catts, E.P. and Goff, M.L. 1992. Forensic entomology in criminal investigations. Annu. Rev. Entomol. 37: 253-272.

Cheong, W.H., Mahadevan, S., and Singh, K.I. 1973. Three species of fly maggots found on a corpse. Southeast. Asian J. Trop. Med. Public Health 4: 281.

Couri, M. 2007. A key to the Afrotropical genera of Muscidae (Diptera). Rev. Bras. Zool. 24: 175184.
Denno, R.F.and Cothran, W.R. 1976. Competitive interactions and ecological strategies of sarcophagid and calliphorid flies inhabiting rabbit carrion. Ann. Entomol. Soc. Am. 69: 109-113.

El-Ghaffar, H.A., Goff, M.L., Shalaby, O.A., ElKady, E.M., and Youssif, N.S. 2008. Seasonal field variations of arthropod development and succession, on exposed rabbit carcasses induced by propoxur in a semi desert region in Egypt. J. Egypt. Ger. Soc. Zool. 56( E): 91-119.

El-Kady, E.M., Essa, Y.E.E., and Shalaby, O.A. 1994. Variations in the blow and flesh flies succession on rabbit carrions killed by different methods. J. Egypt. Ger. Soc. Zool. 13 (D): 451489.

El-Mehy, I., Sief, A., Soliman, E., Hassan, N.A., and Alrouf, T.A. 2015.Application of entomology in some medicolegal issues. Austin J. Forensic Science and Criminology 2: 1036.

El-Samad, L.M. and Youssef, M.H. 2016. Seasonality of insect succession and remains of rabbits treated with amitriptyline (antidepressant drug) in Alexandria, Egypt. J. Adv. Biol. 9: 17831798.

Erzinclioglu, Y.Z. 1990. The larvae of two closely related blowfly species of the genus Chrysomya (Diptera, Calliphoridae). Entomol. Fenn. 1: 151153.

Fremdt, H., Szpila, K., Huijbregts, J., Lindstrom, A., Zehner, R., and Amendt, J. 2012. Lucilia silvarum Meigen, 1826 (Diptera: Calliphoridae)- 
A new species of interest for forensic entomology

in Europe. Forensic Sci. Int. 222: 335-339.

Galal, L. A. A., Abd-El-Hameed, S.Y., and Attia, R.A.H., and Uonis, D.A. 2009. An initial study on arthropod succession on exposed human tissues in Assiut, Egypt. Mansoura J. Forensic Med. Clin. Toxicol. 17: 55-74.

Glassman, D.M. and Crow, R.M. 1996. Standardization model for describing the extent of burn injury to human remains. J. Forensic Sci. 41: 152-154.

Goff, M.L. 1991. Comparison of insect species associated with decomposing remains recovered inside dwellings and outdoors on the Island of Oahu, Hawaii. J. Forensic Sci. 36: 748-753.

Grassberger, M, and Frank, C. 2004. Initial study of arthropod succession on pig carrion in a Central European urban habitat. J. Med. Entomol. 41: 511-523.

Grassberger, M., and Reiter, C. 2001. Effect of temperature on Lucilia sericata (Diptera: Calliphoridae) development with special reference to the isomegalen - and isomorphen-diagram. Forensic Sci. Int.120: 32-36.

Grassberger, M., and Reiter, C. 2002. Effects of temperature on development of Liopygia (= Sarcophaga) argyrostoma (Robineau-Desvoidy) (Diptera: Sarcophagidae) and its forensic implications. J. Forensic Sci. 47: 1332-1336.
Grassberger M., Friedrich, E., Reiter, C. 2003. The blowfly Chrysomya albiceps (Wiedemann) (Diptera: Calliphordiae) as a new forensic indicator in Central Europe. Int. J. Legal Med.117: 75-81.

Greenberg, B. 1991. Flies as forensic indicators. J. Med. Entomol. 28: 565-577.

Greenberg, B. and Kunich, J.C. 2002. Entomology and the law: flies as forensic indicators. Cambridge University Press, Cambridge, UK.

Greenberg, B., and Povolny, D. 1971. Bionomics of flies, pp. 57-83. In: B. Greenberg, Flies and disease, vol 1. Princeton University Press, Princeton. NJ.

Grzywacz, A., Hall, M.J.R., and Pape, T. 2015. Morphology successfully separates third instar larvae of Muscina. Med. Vet. Entomol. 29: 314329.

Grzywacz, A., Hall, M.J.R., Pape, T., and Szpila, K. 2017. Muscidae (Diptera) of forensic importance- an identification key to third instar larvae of the western Palaearctic region and a catalogue of the muscid carrion community. Int. J. Legal Med. 131:855-866.

Gunn, A., and Bird, J. 2011.The ability of the blowflies Calliphora vomitoria (Linnaeus), Calliphora vicina (Rob- Desvoidy) and Lucilia sericata (Meigen) (Diptera: Calliphoridae) and the muscid flies Muscina stabulans (Fallén) and Muscina prolapsa (Harris) (Diptera: Muscidae) to 
colonise buried remains. Forensic Sci. Int. 207:

198-204.

Hafez, M. 1940. A study of the morphology and life history of Sarcophaga falculata Pandellé (Diptera: Sarcophagidae). Bull. Entomol. Soc. Egypt 24: 183-212.

Ibrahim, A.A., Galal, F.H., Seufi, A.M., and Elhefnawy, H.A. 2013. Insect succession associated with corpse's decomposition of the guinea pig Cavia porcellus in Benha city, Egypt. Egypt. Acad. J. Biol. Sci. 5: 1-20.

Introna, F., Campobasso, C.P., and Di Fazio, A. 1998. Three case studies in forensic entomology from Southern Italy. J. Forensic Sci. 43: 210-214.

Kosmann, C., Macedo, M.P., Barbosa, T.A.F., and Pujol-Luz, J.R. 2011. Chrysomya albiceps (Wiedemann) and Hemilucilia segmentaria (Fabricius) (Diptera, Calliphoridae) used to estimate the postmortem interval in forensic case in Minas Gerais, Brazil. Rev. Bras. Entomol. 55:621-623.

Kreitlow, K.L.T. 2010. Insect succession in a natural environment, pp. 251-269. In: J.H. Byrd and J.L. Castner (eds), Forensic entomology: the utility of arthropods in legal investigations, 2nd edition, CRC Press, Boca Raton, Florida.

Lambiase, S. and Camerini, G. 2012. Spread and habitat selection of Chrysomya albiceps (Wiedemann) (Diptera Calliphoridae) in northern Italy: forensic implications. J. Forensic Sci. 57: 799-801.
Lee, H.L., Krishnasamy, M., Abdullah, A.G, Jeffery, J. 2004. Review of forensically important entomological specimens in the period of 19722002. Trop. Biomed. 21:69-75.

Lundt, H. (1964) Ökologishe untersuchungen über tierische beseidlung von Aas im Boden. Pedobiologia 4: 158-180.

Lutz, L., Williams, K., Villet, H., Ekanem, M., and Szpila, K. 2018. Species identification of adult African blowflies (Diptera: Calliphoridae) of forensic importance. Int. J. Legal Med. 132: 831842.

Mariluis, J.C. and Schnack, J.A. 1989. Ecology of the blow flies of an eusynanthropic habitat near Buenos Aires (Diptera, Calliphoridae). Eos (Madrid) 65: 93-101.

Martinez-Sanchez, A., Marcos-Garcia, M.A., and Rojo, S. 2001. First collection of Chrysomya megacephala (Fabr.) in Europe (Diptera: Calliphoride). Pan.-Pac. Entomol. 77: 240-243.

Mashaly, A.M.A. 2016. Entomofaunal succession patterns on burnt and unburnt rabbit carrion. J. Med. Entomol. 53: 296-303.

Matuszewski, S., Szafalowicz, M., and Jarmusz, M. 2013. Insects colonising carcasses in open and forest habitats of Central Europe: Search for indicators of corpse relocation. Forensic Sci. Int. 231: 234-239.

Merritt, R.W., and De Jong, G.D. 2016. Arthropod communities in terrestrial 
environments, pp. 65-91. In: M.E. Benbow, J.K.Tomberlin, and A.M.Tarone (eds), Carrion ecology, evolution, and their applications. CRC Press, Boca Raton, Florida.

Mohamed, S.A. 1984. Survey and taxonomic study of family Calliphoridae (Diptera) in AR Egypt. M.S. Thesis, Ain Shams University, Egypt.

Nuorteva, P. 1977. Sarcosaprophagous insects as forensic indicators, pp. 1072-1095, vol. 2. In: C. G. Tedeschi, W. G. Eckert, and L. G. Tedeschi [eds], Forensic medicine: a study in trauma and environmental hazards. Saunders, Philadelphia.

Pacheco, V.A., Hans, K.R., and VanLaerhoven, S.L. 2017. The relationship between surface area and volume of common blow fly (Diptera: Calliphoridae) oviposition sites and carrion body mass. J. Med. Entomol. 54: 1278-1284.

Pape, T. 1987. The Sarcophagidae (Diptera) of Fennoscandia and Denmark. Fauna Entomol. Scand. 19: 1-203.

Peschke, K., Krapf, D., and Fuldner, D 1987. Ecological separation, functional relationships, and limiting resources in a carrion insect community. Zool. Jb. Syst. Oekol. Geogr. Tiere 114: 241-265.

Povolny, D. and Verves, Y. 1997. The flesh-flies of Central Europe (Insecta, Diptera, Sarcophagidae). Spixiana Suppl. 24: 1-260.

Ramos-Pastrana, Y. and Wolff, M. 2017. Postmortem interval estimation based on
Chrysomya albiceps (Diptera, Calliphoridae) in a forensic case in the Andean Amazon, Caquetá, Colombia. Acta Amazonica 47: 369-374.

Richards, C.S., Price, B.W., and Villet, M.H. 2009. Thermal ecophysiology of seven carrionfeeding blowflies in Southern Africa. Ent. Exp. Appl. 131:11-19.

Rivers, D.B. and Dahlem, G.A. 2014. The science of forensic entomology. John Wiley \& Sons., Ltd, West Sussex, UK.

Rognes, K. 2002. Blowflies (Diptera, Calliphoridae) of Israel and adjacent areas, including a new species from Tunisia. Entomol. Scand. Suppl. 59, 148 pp.

Salem, H.H. 1935. The Egyptian species of the genus Sarcophaga. Publ. Egypt Univ. Fac. Med. 5: 1-61.

Sawaby, R.F., El Hamouly, H., and Abo-El Ela, R.H. 2018. Diagnosis and keys of the main dipterous families and species collected from rabbit and guinea pig carcasses in Cairo, Egypt. J. Basic Appl. Zool. 79:10, DOI 10.1186/s41936018-0018-6.

Schoenly, K. 1992. A statistical analysis of successional patterns in carrion-arthropod assemblages: Implications for forensic entomology and the determination of the postmortem interval. J.Forensic Sci. 37:14891513. 
Schoenly, K. and Reid, W. 1987. Dynamics of heterotrophic succession in carrion arthropod assemblages: Discrete series or a continuum of change? Oecologia 73:192-202.

Skidmore, P. 1985. The biology of the Muscidae of the world. Junk, Dordecht, Netherlands.

Smeeton, W.M.I., Koelmeyer, T.D., Holloway, B. A., and Singh, P. 1984. Insects associated with exposed human corpses in Auckland, New Zealand. Med. Sci. Law 24: 167-174.

Smit, B. 1931. A study of the sheep blow-flies of South Africa. 17th Report of the Director of Veterinary Services and Animal Industry. Union of South Africa, pp. 299-421.

Smith, K.G.V. 1986. A manual of forensic entomology. British Museum (Natural History), London and Cornell University Press, Ithaca, NY.

Sukontason, K., Narongchai, P., Kanchai, C, et al. 2007. Forensic entomology cases in Thailand: a review of cases from 2000 to 2006. Parasitol. Res.101:1417-1423.

Szpila, K. 2010. Key for the identification of third instars of European blowflies (Diptera: Calliphoridae) of forensic importance, pp. 43-56. In: J. Amendt, M.L. Goff, C.P. Campobasso, and M., Grassberger (eds), Current concepts in forensic entomology. Springer, Dordrecht, Netherlands.

Szpila, K., Richet, R. and Pape, T. (2015). Third instar larvae of flesh flies (Diptera:
Sarcophagidae) of forensic importance - critical review of characters and key for European species. Parasitol. Res. 114: 2279-2289.

Tantawi, T.I. and El-Kady, E.M. 1997. Identification of third instar larvae of forensically important flies (Diptera: Calliphoridae, Sarcophagidae and Muscidae) in Alexandria, Egypt. J. Egypt. Ger. Soc. Zool. 23(E): 1-20.

Tantawi, T.I., El-Kady, E.M, Greenberg, B., and El-Ghaffar, H.A. 1996. Arthropod succession on exposed rabbit carrion in Alexandria, Egypt. J. Med. Entomol. 33: 566-580.

Tomberlin, J.K., Mohr, R., Benbow, M.E., Tarone, A.M., and VanLaerhoven, S. 2011. A roadmap for bridging basic and applied research in forensic entomology. Annu. Rev. Entomol. 56: 401-421.

Vanin, S., Caenazzo, L., Arseni, A., Cecchetto, G., Cattaneo, C., and Turchetto, M. 2009. Records of Chrysomya albiceps in northern Italy: an ecological and forensic perspective. Mem. Inst. Oswaldo Cruz, Rio de Janeiro 104: 555-557.

Vanin, S., Gherardi, M., Bugelli, V. and Di Paolo, M. 2011. Insects found on a human cadaver in central Italy including the blowfly Calliphora loewi (Diptera, Calliphoridae), a new species of forensic interest. Forensic Sci. Int. 207: e30-e33.

Verves, Y., Bartak, M., and Kubik, S. 2018. Checklist of flesh flies of Turkey (Diptera, Sarcophagidae). ZooKeys 743: 95-136. 
Wells J.D. 1991. Chrysomya megacephala

(Diptera: Calliphoridae) has reached the continental United States: review of its biology, pest status, and spread around the world. J. Med. Entomol. 28: 471-473.

Wells, J.D. and Kurahashi, H 1994. Chrysomya megacephala (Fabricius) (Diptera: Calliphoridae) development: rate, variation and the implications for forensic entomology. Jap. J. Sanit. Zool. 45: 303-309.

Wells, J.D. and LaMotte, L.R. 2010. Estimating the postmortem interval, pp. 367-388. In: J.H. Byrd and J.L. Castner (eds), Forensic entomology: the utility of arthropods in legal investigations, 2nd edition, CRC Press, Boca Raton, Florida.

Wells, J.D., Byrd, J.H., and Tantawi, T.I. 1999. Key to third-instar Chrysomyinae (Diptera: Calliphoridae) from carrion in the continental United States. J. Med. Entomol. 36: 638-641.
Wells, J.D., Pape, T., and Sperling, F.A.H. 2001. DNA-based identification and molecular systematics of forensically important Sarcophagidae (Diptera). J. Forensic Sci. 46: 1098-1102.

Williams, K.A., Richards, C.s., and Villet, M.H. 2014. Predicting the geographic distribution of Lucilia sericata and Lucilia cuprina (Diptera: Calliphoridae) in South Africa. Afr. Invert. 55: 157-170.

Zerriya, M.G.M, Hammad, K.M., Fouda, M.A., Al-Dali, and Kabadaia, M.M. 2015. Forensicinsect succession and decomposition patterns of dog and rabbit carcasses in different habitats. J. Entomol. Zool. Stud. 3: 473-482.

Zumpt, F. 1965. Myiasis in man and animals in the Old World. Butterworths, London. 